\title{
FUNDAMENTAL CANCER RESEARCH
}

\footnotetext{
$\mathrm{T}$
} HE sixteenth annual symposium on fundamental cancer research was held at the M. D. Anderson Hospital and Tumor Institute, Houston, during March 1-3, and its title ("Conceptual Advances in Immunology and Oncology") is indicative of the renewed interest in the immunological approach to the problem of cancer. It is equally significant that two out of the three days should have been devoted to fundamental immunology: even those who remain profoundly sceptical of the possibility of an allembracing immunological interpretation of the cancer problem must concede that many of the techniques used in immunology are proving to be of immense value in its study.

The conference began auspiciously with discussions by Sir Macfarlane Burnet and F. Haurowitz on theories of immunity, one taking up the cudgels on behalf of an elective theory implying some kind of genetically built-in cellular responsiveness which is merely triggered off by antigen, and the other championing the instructive theory, which postulates that it is antigen, acting as a template, which impresses specific complementariness on the newly formed $\gamma$-globulin of cells. Burnet made it clear that although he could no longer believe in the truth of the clonal selection hypothesis as originally proposed by himself he still felt that the experimental evidence - not least his own, concerned with graft-against-host reactions of cells transplanted to the chorioallant oic membrane of the chick embryo-pointed to an elective theory; it would be extremely difficult to reconcile any other kind of theory with the fact that, during the course of development, the body 'learns' not to react against its own substances. Haurowitz, on the other hand, described experiments which indicate that antigen may persist intracellularly for many months and that antibody may be formed in very small amounts as long as one year after primary stimulation with bovine serum albumin. He felt that re-interpretation of the anamnestic response with these facts in mind was perfectly in line with the idea that antigen acts in an instructive capacity. However, both speakers agreed that at present there could be no final proof either one way or the other, and that in the last analysis a compromise between these two concepts may turn out to be nearest to the truth.

To fill the gap in the programme caused by the regrettable absence of $N$. K. Jerne, several short papers were read by the 'home team'. Of these, the most relevant to the problem of antibody formation was that of J. J. Trentin, who outlined a technique which, he thought, should at last provide a conclusive test of the clonal selection hypothesis. The technique entailed the re-population of the lymphoid organs of lethally irradiated mice with cells thought to belong to a single 'clone' and the subsequent challenge of these mice with four Shigella antigens. In giving his results, Trentin was careful to stress that much work remained to be done before they could be accepted as conclusive; but it appeared that the majority of a small number of mice was able to respond to several of the antigens. However, the crucial assump- tion-that the cells were, in fact, derived from a single donor strain cell-remained to be proved.

One of the most exciting advances in recent years has been the recognition that certain diseases such as Hashimoto's disease and acquired hæmolytic anæmia are caused by autoimmune responses, and a number of other diseases are now strongly suspected of an autoimmune origin. In discussing theories of autoimmunity, W. Dameshek suggested that experimentally induced 'runt disease' (which is due to the immunological response of genetically foreign lymphoid cells against the tissue antigens of the host) provided a revealing model for the autoimmune disorders. Autoimmunity could be antigen-mediated as in thyroiditis, which is almost certainly made possible by the fact that antigen in the form of thyroglobulin is sequestered during embryonic development and is therefore unable to induce immunological tolerance in the body's antibody-forming cells; or it could be due to abnormal immunologically competent cells owing their existence either to genetic causes or to somatic mutation.

Several papers were devoted to the control mechanisms of antibody synthesis. In describing the detailed cellular changes which occur when antigen is introduced into sensitized animals, F. J. Dixon provides the morphological background against which all immunological reactions must be viewed. He particularly stressed the fact that the nature of the morphological changes depends to a very large extent on whether immunity is mediated through cells or through serum. D. H. Sussdorf critically reviewed past and present experiments designed to reveal antibody activity in cell-free systems and pointed out many of the pitfalls inherent in experiments of this kind. R. W. Dutton described a series of experiments revealing the capacity of sensitized spleen cells to synthesize deoxyribonucleic acid (DNA) in vitro: addition of antigen stimulated the incorporation of thymidine labelled with carbon-14 into the DNA of the spleen cell, a phenomenon which was specific for the antigen with which the cell donor had been sensitized. Increase in thymidine incorporation was accompanied by an increase in the number of engaged cells rather than by an increase in the degree of incorporation by the same number of cells.

The properties of interferon (first uncovered by $\mathrm{A}$. Isaacs at the National Institute for Medical Research, London) were comprehensively reviewed by S. E. Grossberg. Interferon was the name given to certain proteins produced by cells after exposure to viruses, and these substances had the power to protect other cells against infection. The resistance conferred by interferon was non-specific for virus, but it showed a curious species-specificity in the sense that interferon extracted, for example, from mouse tissues would not protect chicken cells. The action of interferon was intracellular, for it had been shown not to affect vimus adsorption and penetration; nor was it, in all probability, able to influence release of virus. Although its action was still far from clear, Grossberg 
suggested that it might well be based on the uncoupling of oxidative phosphorylation.

R. S. Schwartz discussed the chemical suppression of immunity, that is, the elimination of the immunological response by prolonged treatment with antimetabolites such as 6-mercaptopurine. Although in a limited clinical study some of the patients suffering from hæmolytic anæmia responded well to chemotherapy, Schwartz went out of his way to stress the fact that, owing to the toxicity of the drug, treatment of this kind could be applied only with the most expert clinical and laboratory supervision. He also raised the interesting if speculative point that treatment of tumour-bearing patients with chemical agents capable of suppressing immunological responses might well deprive the patient of the means of resistance to the tumour.

A whole day was set aside for the discussion of the nature of the antigen-antibody reaction. $\mathrm{C}$. W. Parker explained that for certain kinds of antigenantibody reactions the spectrofluorometric method, which depends on a decrease in fluorescence when antibodies specifically interact with haptens, has important advantages over other mothods. Using this method he had confirmed that R. R. Porter's immune $\gamma$-globulin fractions I and II (produced by digestion with papain) titrated as 'univalent molecules', but that fraction III was inactive. J. J. Cebra showed that water-insoluble papain may be used to great effect in the examination of the structure of antigen-antibody complexes, their molecular weights and the valence of the antigens. That the treatment of antibody with pepsin, followed by reduction of a single highly labile disulphide bond, can produce fragments closely resembling Porter's fractions I and II was demonstrated by $\mathbf{A}$. Nisonoff, who went on to describe the formation of 'hybrid' antibodies by the oxidative coupling of univalent sub-units obtained from antibodies of two different specificities. Nisonoff also presented evidence suggesting that hybridization had occurred as a result of random recombination.

Z. Ovary described experiments which showed that although non-aggregated low molecular weight haptens with one determinant group did not provoke passive cutaneous anaphylaxis they could inhibit it, as well as noutralize in vitro specific rabbit or guinea pig antibody. When a second determinant group was added in vitro, neutralization was again complete but in vivo results were variable: with some guinea pig and rabbit sera the hapten now provoked passive cutaneous anaphylaxis, whereas with other guinea pig sera it acted only in the feeblest manner.

The chemical nature of the combining site of antibody molecules was discussed by $D$. Pressman, who made the point that owing to the heterogeneity of antibodies the study of anti-hapten antibodies was of the greatest value; unlike antibodies directed against proteins or other natural substances, such antibodies were directed against a single known chemical group. ing. Pressman also said that there was now reasonable evidence from pepsin and papain experiments indicating that antibodies of even a single molecular weight may be of several different types, and that the fractions discovered by Porter were more complex than had originally been thought. J. R. Marrack suggested that the formation of aggregates, joined by specific bonds between bivalent antigens and multivalent antibodies, was not sufficient to account for precipitation. One of several possible reasons for failure to precipitate was the possibility that, because antigens carried determinants of various kinds, univalent antibody to one of the determinants was present in the system.

Finally, O. J. Plescia explained that although pure DNA had not been shown to be antigenic, it had been possible to prepare it in an immunogenic form from Brucella abortus. Several antigens were associated with this DNA; those susceptible to treatment with DNase were almost certainly DNA-carbohydrate complexes which could be dissociated only with the greatest difficulty, and the released DNA had comparatively little antigenicity. The antigenic groups were therefore unlikely to be part of the DNA molecule.

The highlight of the symposium was the presentation of the Bertner Foundation Award to G. D. Snell, director of the Roscoe B. Jackson Memorial Laboratory - an award given for outstanding achievement in the field of cancer research. In his Foundation Lecture on the immunology of tissue transplantation, Snell gave a comprehensive and up-to-date survey of a field which is continuing to change very rapidly and to which he and his colleagues have made such important contributions. He stressed that it had become necessary to distinguish between two kinds of immunological response, the one mediated through conventional serum antibodies and the other through antibodies associated with circulating lymphoid cells. Although both responses frequently occurred side by side, leukotic cells and normal lymphoid cells were susceptible to serum antibodies whereas most solid tumours and normal tissues such as skin were susceptible only to a cellular immunity. Snell also reviewed the phenomenon of immunological enhancement and made it clear that he and his colleague, H. J. Winn, had come to the conclusion that enhancement was brought about by central inhibition of the immunological response by serum antibodies.

Snell's lecture set the scene for a session devoted to tissue transplantation and immunological tolerance. L. Brent described experiments which confirmed that unresponsiveness to skin homografts can be brought about in adult mice by repeated injection of allogeneic hybrid spleen cells. He and G. Gowland had analysed this unresponsiveness and had come to the conclusion that it had almost all the properties of neonatally induced tolerance; although different methods had to be used to induce them, these two phenomena were probably identical at a cellular level. J. J. Trentin and J. Session described experiments using chromosome marker methods which indicated that in mice made tolerant at birth with allogeneic spleen cells the lymphoid tissues were largely repopulated with donor strain cells. They also found that tolerance of skin grafts was more durable when it was induced with hybrid rather than with parental strain cells. That donor cells persist in mice made tolerant with lymphoid cells either at birth or in adult life was demonstrated very clearly by C. Martinez, who used the spleens of tolerant mice to induce tolerance of donor strain antigens in isogeneic new-born mice. The degree of repopulation of the hosts' lymphoid tissue depended largely on the genetic relationship between donor and recipient strains and also on the manner in which tolerance had been brought about in the first instance.

M. W. Chase reviewed the work he and his colleagues had done on the acquisition of immunological tolerance of simple chemical allergens such as picryl chloride; guinea pigs repeatedly fed with such substances were unable to respond to the allergen with 
a delayed-type contact hypersensitivity or with circulating antibodies. When especially powerful antigens were used abundant serum antibody was formed but inhibition of delayed hypersensitivity remained unaltered. Chase felt that present theories of tolerance would have to be amended so as to take these facts into account. In a most interesting contribution, $M$. Feldman explained that he and his colleagues had shown that the immunological responsiveness of sub-lethally irradiated rats could largely be restored by the injection of cells from normal animals together with the antigen (sheep red blood cells). This was also true for rats made unresponsive to human serum albumin by treatment with 6-mercaptopurine: immunological responsiveness could be restored not only with spleen cells but with cell-free extracts and DNA-digests as well. Feldman believed that these experiments were incompatible with the clonal thoory of tolerance.

The final session was concerned with the question of cancer-specific antigens. The papers by $\mathrm{K}$. Habel and H. O. Sjögren were beautifully complementary in demonstrating that the cells of tumours induced by polyoma virus possessed a new antigen which was foreign to the host. The experimental evidence was partly based on the observation that mice can be made resistant to the tumour by pre-treatment with the virus or with virus-induced tumour cells; but Habel also showed that resistance could be transferred with lymph node cells but not with serum from resistant mice, and that tolerance of the cellular antigen could be induced in new-born mice. In addition, Sjögren confirmed that methylcholanthreneinduced tumours, too, have a new cellular antigen. The antigenic properties of methylcholanthreneinduced tumours were discussed by $R$. T. Prehn, who stressed that, in contrast to polyoma virus-induced tumours, immunological cross-reactions among various tumours wero rare. The fact that antigenicity was sometimes lost after repeated transplantation sug- gested the possibility that non-antigenic tumour cell variants had been selected by a hostile environment. Prehn suggested that several experimental observations indicated that one of the principal facets of carcinogenic activity might be the suppression of immunological responsiveness by the carcinogens.

B. Björklund described the production in horses of a cancer-specific antiserum following sensitization with sixty human carcinomas. This antiserum was specific for human neoplastic cells because its cytotoxic activity was retained after absorption with normal human cells. Björklund's conclusion that human carcinomas are characterized by specific antigens was not accepted by all immunologists present.

W. Braun et al. claimed to have shown that DNA digests from calf thymus or the spleens of very young mice reduced the incidence of spontaneous tumours when injected repeatedly into young mice. Furthermore, pretreated mice rejected transplantable tumours obtained from untreated old mice - a finding which was complicated by the observation that the same animals died more quickly of growing tumours when challenged for a second time two months later. Finally, R. H. Wilson described a clinical study in which 32 patients with terminal malignant disease were injected with their own tumour cells emulsified with hyaluronidase and Freund's adjuvant. A rise in specific serum antibody titre occurred in 20 patients, and Wilson et al. concluded that a specific antigen must have been present in the neoplastic cells of these patients.

The symposium was attended by many hundreds of cancer research workers, and it undoubtedly succeeded in giving them an excellent bird's-eye view of the manifold new developments in immunology and cancer research. However, the very size of such a conference seriously limits the value of the discussions, and this is to be regretted.

Leslite Brent

\section{OBITUARIES}

\section{Mr. Fred Scholefield, M.B.E.}

Fred Scholefield, who died on March 10 at his home in Hale, Cheshire, at the age of seventyeight, and who spent almost the whole of his long professional life in the service of tinctorial technology, will best be remembered as the head of the Department of Textile Chemistry in the Colloge of Scionee and Technology, Manchester, a department which he brought into being. He came late to the service of university education, for, after a meritorious performance as a student in the Departments of Chemistry and of Dyeing and Tinctorial Chemistry at the Yorkshire College (later the University of Leeds), he was for twenty-two years engaged in tho industrial practice of textile dyeing and allied chemical treat ments, becoming ultimately the chief chemist and works manager of Burgess, Lodward and Co., a large yarn-processing firm near Manchester.

In an old industry in which traditional usages and modern chemical and engincering discovery need to be promptly combined by the more enterprising firms, Scholefield foresaw more strongly than many of his generation the need for a much groater number of carefully and soundly trained technologists than seemed to be in prospect at the end of the First
World War. In 1926 he gave up his industrial position to join the Department of Applied Chemistry at the College, taking the place left vacant by the death of Edmund Knecht and the retirement of Julius Huebner. Soon after his arrival he was able to have a separate Department established, of which he was to remain the head until his effective retirement from academic work in 1951. During his régime the Department developed greatly in activity and importance, students came from many parts of the world and the record of research and teaching was very substantial taking into account the small numbers of his staff.

Scholefield's main interest in the field of dyeing research was in the oxidative changes brought about in collulosic and other fibres when they were dyed with certain vat dyes, and activation occurred either by light or through other chemical agencies. Although later workors have extended our knowledge of the fundamental mechanisms on which these phenomena could be based, there is, even now, very little further understanding of the distinctive effects of specific dyes in actual textile products.

Scholefield was a lucid and inspiring teacher, a kindly, sociable and goncrous man, widely read and widely travelled, with many friends in Britain and 